\title{
HISTORY OF FORMATION OF E-COMMERCE ENTERPRISES AS SUBJECTS OF INNOVATIVE ENTREPRENEURSHIP
}

\author{
Vladimir Simakov ${ }^{1}$
}

\begin{abstract}
In the article the history of the formation of e-commerce enterprises as subjects of innovative entrepreneurship is analyzed. The list of stages of genesis of formation of e-commerce enterprises as subjects of innovative entrepreneurship is determined. The specifics of each of the historical periods are described. In the last decade, the concept of the essence of the benefits and specifics of the functioning of e-commerce as the latest phenomenon of the world economy has become the subject of attention not only of practitioners but also of scientists. This is largely due to the need to solve with the help of new scientific solutions being developed in this area, specific problems of practice, which will assess and improve efficiency, as well as supplement the tools of e-commerce with new approaches. At the same time, such research should be based on the study of the genesis and identification of current trends in the formation of e-commerce enterprises as subjects of innovative entrepreneurship, which determines the relevance of the topic of this article. E-business or e-commerce is traditionally interpreted as the sale of goods over the Internet. In a broader sense, e-commerce can be interpreted as the use of electronic means of transmission to participate in exchange, including the purchase and sale of goods and services, which requires transportation, both physically and digitally, from one place to another.
\end{abstract}

Key words: history, enterprises, e-commerce, subjects of innovative entrepreneurship, economy.

JEL Classification: L81, L26

\section{Introduction}

Digital technologies have changed the global economy significantly in recent decades and continue to change. Value creation processes for customers have shifted from the production of physical goods to a service-oriented economy, information and intelligence as the main sources of value creation and profit. At the heart of this economic transformation is e-commerce.

In the last decade, the concept of the essence of the benefits and specifics of the functioning of e-commerce as the latest phenomenon of the world economy has become the subject of attention not only practitioners but also scientists (Roberts, Zahay, 2017; Dvoretsky, Zharnikova, SobolevaTereshchenko, 2019). This is largely due to the need to solve with the help of new scientific solutions being developed in this area, specific problems of practice, which will assess and improve efficiency, as well as supplement the tools of e-commerce with new approaches.

At the same time, such research should be based on the study of the genesis and identification of current trends in the formation of e-commerce enterprises as subjects of innovative entrepreneurship, which determines the relevance of the topic of this paragraph.

E-business or e-commerce is traditionally interpreted as the sale of goods over the Internet (Lazneva, Dolgopolova, 2019). In a broader sense, e-commerce can be interpreted as the use of electronic means of transmission to participate in the exchange, including the purchase and sale of goods and services, which requires transportation, both physically and digitally, from one place to another (Malovichko, 2015).

In this context, in our opinion, it is important to understand the importance of e-commerce as an environment that is created and developed in order to facilitate (accelerate, increase convenience for buyers and sellers, etc.) exchange of goods. Thus, e-commerce is becoming a driving force in the development of modern trade and through its active development it is largely inferior to traditional organizational forms of trade (department stores, branded stores, etc.).

Corresponding author:

${ }^{1}$ PJSC "Novokramatorsky Engineering Factory", Ukraine. 


\section{Presentation of research material}

E-commerce is a specific form of innovative entrepreneurship that has gained significant benefits in the trade of goods due to the significant potential of the Internet. The main reason for the success of business in the field of e-commerce according to researchers (Melnychuk, 2014) has its coverage: the e-commerce business operates on an online platform, and today, using the Internet, there is the potential to gain a much larger number of customers than in a real store.

There are many forms of commercial transactions that can take place in everyday life from business to business, or B2B, such as electronic data interchange, auction markets, and so on. Commercial transactions can also take place in $\mathrm{B} 2 \mathrm{C}$ or business with consumers, such as online retail and electronic brokerage services. E-commerce has tried to take advantage of savings by using a single data center to reduce system errors and processing time, a high degree of personalization of the product or service to meet customer needs and customer interaction with databases at very low marginal cost (Shaleva, 2011).

Thus, e-commerce has been and remains an area where innovations are actively implemented and disseminated, so it is not only a form of innovative entrepreneurship, but also an environment for testing and implementing innovations that enhance e-commerce and innovative entrepreneurship in general.

E-commerce has a rich history, from primitive electronic data transactions in the 1960s and the first online retail transactions in 1994, to the modern popularity of e-commerce giants such as Amazon and eBay. Outlining certain stages in the history of e-commerce should be based on scientific approaches to this issue, which makes it possible to reveal the content of each relevant stage in the context of the factors that led to its occurrence and actualization.

As early as the 1960s, companies conducted electronic transactions through primitive computer networks. Thanks to electronic data interchange (EDI), they were able to exchange business documents with machines from other companies. During the same period, the military created the ARPAnet network, which allowed the dissemination of important information in the event of a nuclear attack. These innovations laid the foundation for e-commerce. In fact, when ARPAnet switched to Transmission Control Protocol and
Internet Protocol (TCP / IP) in 1982, it used the same technologies that are used today on the Internet (Moore).

Originally, the term "e-commerce" meant the process of conducting commercial transactions electronically using leading technologies such as electronic data interchange (EDI) and electronic means of transmission (EFT), which allowed users to exchange business information and enter into electronic transactions. The ability to use these technologies appeared in the late 1970s and allowed commercial companies and organizations to send commercial documents electronically.

In the early 1980s, the main owners of computers were research universities. However, those who had access to computers could send e-mails and exchange documents over networks such as BITNET and USENET. For home PC users, CompuServe was the main provider of bulletin boards, chat rooms, and more. CompuServe introduced the Electronic Mall in 1984, which allowed users to make deferred purchases in more than 100 online stores. The service was not very successful, but it was one of the first examples of online retail. Subsequently, in 1991, the National Science Foundation lifted the ban on commercial use of the Internet (Zharnikova, 2019). In our opinion, this historic step has made e-commerce possible in the form that is currently known, and has significantly contributed to the dynamization of this form of innovative entrepreneurship.

The next important issue was security, which is an important element of the effective functioning of the technical and technological base of e-commerce. In 1994, Netscape 1.0 released a protocol called Secure Socket Layer (SSL), which secures both the sending and receiving sides of an online transaction. SSL provided the ability to encrypt personal information on the network (Moore). Ensuring the security of trade through e-commerce, in our opinion, was the factor that made it possible to combine the potential of e-commerce with online payments and created the foundations for e-commerce as a leading trend in world trade.

Shortly afterwards, to ensure the required level of security, the first third-party credit card processing companies were established, which significantly increased the opportunities for financial transactions in e-commerce transactions and became a significant driver of e-commerce development in the world. That's what made the 
first-ever secure online transaction possible: On August 11, 1994, The New York Times reported that a man named Phil Brandenberger of Philadelphia had purchased the Sting singer's album from his computer. This has opened up opportunities for innovative entrepreneurs to benefit significantly from the new trend. It should also be noted that this opportunity was the impetus for the emergence of the next (1995) Amazon and eBay and a significant acceleration of e-commerce after that (Hagiu, Wright, 2015). Largely thanks to these two companies, modern e-commerce retailers enjoy a highly developed and specialized market, and users can buy almost any product online.

- E-commerce is also a smart choice for entrepreneurs, especially because launching an online store no longer requires large overhead costs and large technical knowledge. Thus, according to BigCommerce, the average cost of creating an online store in 1999 was about 100,000 US dollars, and this did not take into account the purchase of goods, warehouses or delivery logistics. At the moment, the cost of launching an online store can be as little as \$ 30 (Malyuta, Ogol, 2019). Therefore, in our opinion, a significant reduction in the cost of entering the market for new market participants should be included in the list of important trends and factors in the development of e-commerce in the global dimension.

- In 2000, a large number of commercial companies in the United States and Western Europe introduced their services on the World Wide Web. At this time, the meaning of the term "e-commerce" has changed. People began to define it as "the process of buying available goods and services over the Internet using secure connections and electronic payment services." Although the dotcom crash in 2000 failed, and many e-commerce companies disappeared, retailers realized the benefits of e-commerce and began adding such opportunities to their websites (for example, after the Webvan online store went bankrupt, two supermarket chains, Albertsons and Safeway, began using e-commerce to allow their customers to buy products online). By the end of 2001, the largest form of e-commerce, the Businessto-Business (B2B) model, had about $\$ 700$ billion in transactions. Thus, in our opinion, this period of e-commerce can be considered a stage of dynamic growth and entry into the trajectory of sustainable growth of this form of innovative entrepreneurship in developed countries, which ultimately gave impetus to the growth of e-commerce worldwide.
- This view is supported by the fact that, according to available data (Worldwide Retail and Ecommerce Sales: eMarketer's Estimates for 2016-2021), e-commerce sales continued to grow over the next few years, and by the end of 2007 e-commerce sales accounted for 3.4 percent of total world trade sales. - In the table. 1 consistently presents the main events that influenced the development of e-commerce as a form of innovative entrepre-neurship.

- This table clearly shows certain milestones that caused:

- the emergence of e-commerce as an effective form of business organization (for example, the invention of e-shopping in 1979, the launch in 1982 of the first e-commerce platform and in 1992 - an online platform for selling books, etc.); - events that significantly intensified the development of e-commerce (especially the emergence and operation of Amazon, eBay and other large trading platforms, etc.);

- events that contributed to the transformation of e-commerce to the current state (development of online payments, activation of social networks as an environment for the spread of e-commerce, etc.).

In general, the analysis of existing research has shown that at the moment there is no structured representation of the stages of formation and development of e-commerce as a form of innovative entrepreneurship. With this in mind, the author of this paper proposes to distinguish certain stages of development of e-commerce in terms of what effect was achieved in a certain historical period under certain events that affected the development of e-commerce. Yes, in the works (Tardaskina, Strelchuk, Tereshko, 2011; Shaleva, 2011; Kaluzhsky, 2014; Khovrak, 2013) describes the advantages of e-commerce development, which should be taken into account when building an author's system of phasing.

The author of this paper as a criterion for highlighting the stages of development of e-commerce as a form of innovative entrepreneurship proposes to determine a certain effect that was achieved in a certain historical period under certain events that affected the development of e-commerce. This effect can be considered as a separation criterion if it is:

- confirmed by historical data and trends in e-commerce;

- can be clearly formulated and distinguished from the set of results of e-commerce development as a form of innovative entrepreneurship. 
Vol. 1, No. 1, 2020

Table 1

The main events that contributed to the development of e-commerce

\begin{tabular}{|c|l|}
\hline Year & \multicolumn{1}{|c|}{ Major events in the field of e-commerce } \\
\hline 1969 & The first large e-commerce company was founded - CompuServe. \\
\hline 1979 & Michael Aldrich invents e-shopping. \\
\hline 1982 & Boston Computer Exchange is launched as one of the first e-commerce platforms. \\
\hline 1992 & Book Stacks Unlimited is launched as one of the first online bookstores. \\
\hline 1994 & Netscape launches Netscape Navigator, a web browser, making it easier for users to search the web. \\
\hline 1995 & Launch Amazon and eBay. \\
\hline 1998 & PayPal is launched as an online payment system. \\
\hline 1999 & Alibaba.com is launched. \\
\hline 2000 & Google launches AdWords as an online advertising search tool. \\
\hline 2005 & Amazon launches Amazon Prime with accelerated fixed delivery for users. \\
\hline 2005 & Esty, an online platform for launching handmade and vintage goods. \\
\hline 2009 & BigCommerce is launched as an online store platform. \\
\hline 2009 & Founded Square, Inc. \\
\hline 2011 & Google Wallet is launched as an online payment system. \\
\hline 2011 & Facebook is launching sponsored stories as a form of early advertising. \\
\hline 2011 & The Stripe service starts \\
\hline 2014 & Apple Pay is launched as a form of mobile payment. \\
\hline 2014 & Jet.com is launched. \\
\hline 2017 & Introduce posts on Instagram. \\
\hline 2017 & Cyber Monday sales exceed \$ 6.5 billion \\
\hline
\end{tabular}

Source: compiled on the basis of the analysis carried out in this paper and (Moore)

Therefore, the author, based on the above criteria, proposes to identify such stages:

1. The stage of formation of e-commerce as a form of innovative entrepreneurship.

Period - 1969-1995

Highlights (shown in Table 1): Development of Internet services that have created opportunities for the spread of e-commerce and the creation of a data security system and online payments.
2. The stage of ensuring the global presence of e-commerce as a form of innovative entrepreneurship.

Period - 1995-2000

Main events (shown in table 1): appearance on the market Amazon i eBay, Alibaba.com.

3. The stage of ensuring the reduction and optimization of e-commerce costs as a form of innovative entrepreneurship, including-increasing

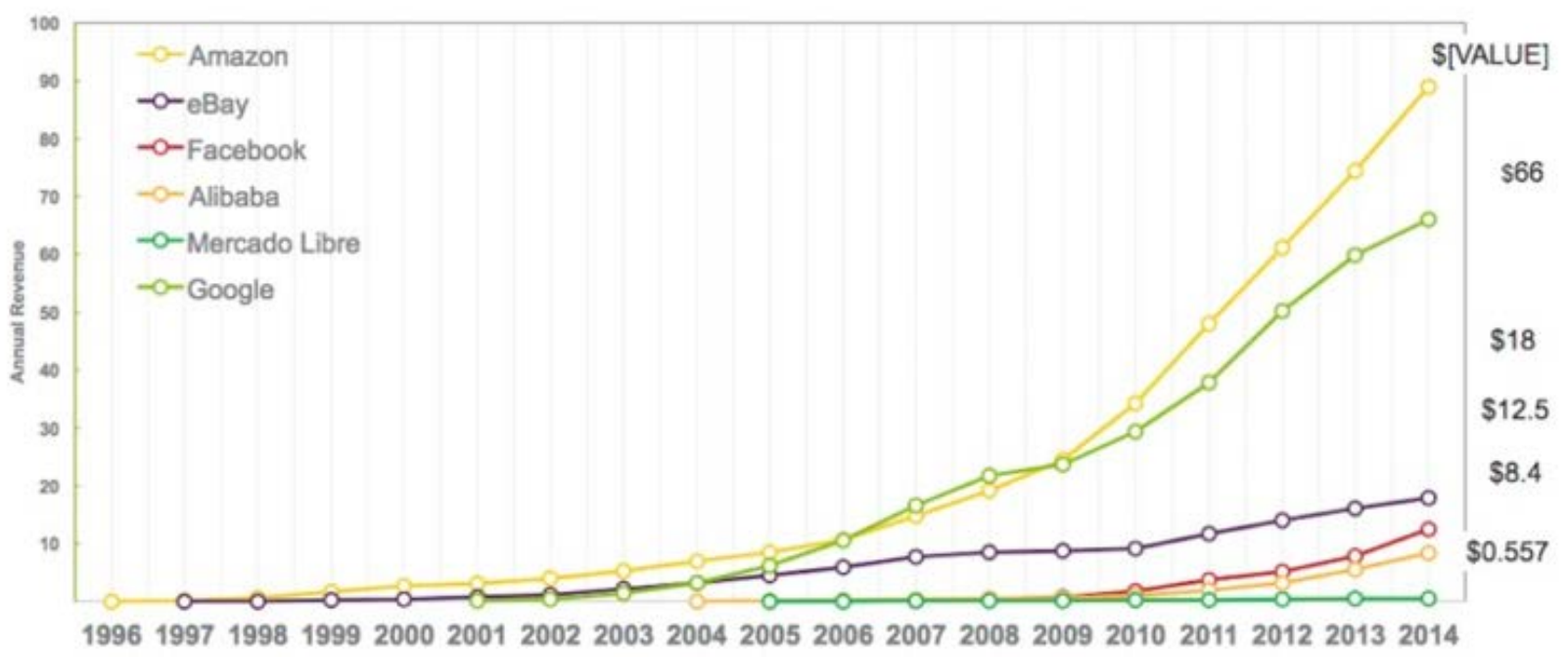

Figure 1. Dynamics of annual profits of leading companies whose activities are based on e-commerce

Source: (Moore; United States: retail e-commerce sales 2017-2024) 


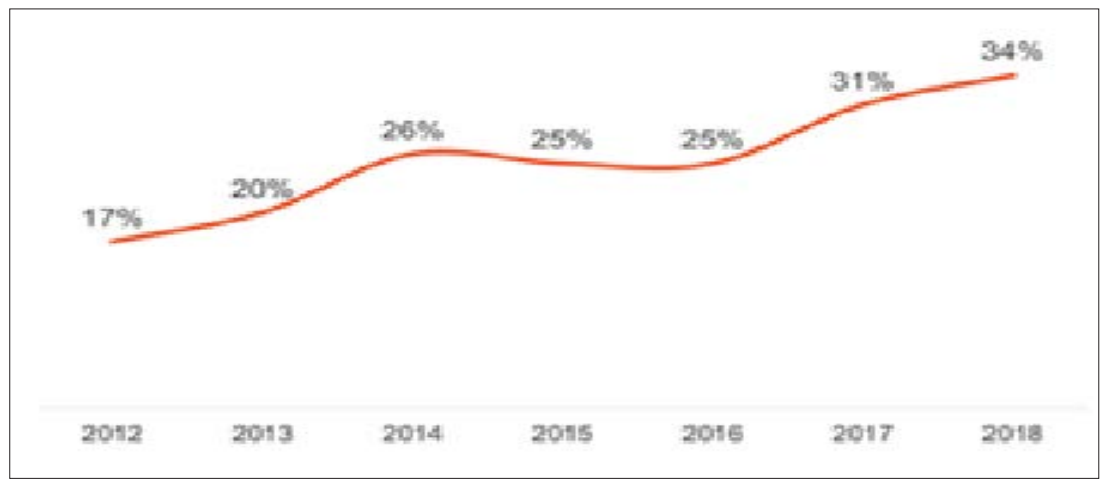

Figure 2. Dynamics of online shopping in Ukraine in 2012-2018

Source: (TOP 10 best online stores in Ukraine 2018-2019)

\begin{tabular}{|c|c|}
\hline rozetka.com.ua & 57.44 \\
\hline allo.ua & 1283 \\
\hline citrus.ua & 11.89 \\
\hline comfy.ua & 7.31 \\
\hline makeup.com.ua & 6.93 \\
\hline foxtrot com us & 5.27 \\
\hline 27 . บa & 5.13 \\
\hline kasta ua & 4.57 \\
\hline tua & 4.56 \\
\hline moyo.ua & 3.53 \\
\hline eldorado va & 3 \\
\hline intertop.ua & 2.38 \\
\hline privatmarket.ua & 2.23 \\
\hline exist ua & 2.02 \\
\hline parfums.ua & 2.02 \\
\hline stylus ua & 1.95 \\
\hline leboutique.com & 1.94 \\
\hline dok dbroker.com ua & 1.76 \\
\hline lamoda ua & 1.74 \\
\hline obilluck.com.us & 1.65 \\
\hline
\end{tabular}

Figure 3. Leaders of the e-commerce market of Ukraine in the number of visits in millions per year in 2019

Source: (TOP 10 best online stores in Ukraine 2018-2019)

the efficiency of advertising costs through the development of advertising services.

Period - 2000-2005

Main events (shown in table 1): appearance on the market AdWords, Amazon Prime.

4. The stage of increasing competition and the emergence of new innovative solutions in the field of e-commerce as a form of innovative entrepreneurship.

\section{Period - 2005-2010}

Main events (shown in table 1): the emergence of new platforms, finding ways to personalize the offer to consumers.

5. The stage of increasing the convenience and speed of interaction between seller and buyer in the field of e-commerce as a form of innovative entrepreneurship, including - the convenience of payment services. 


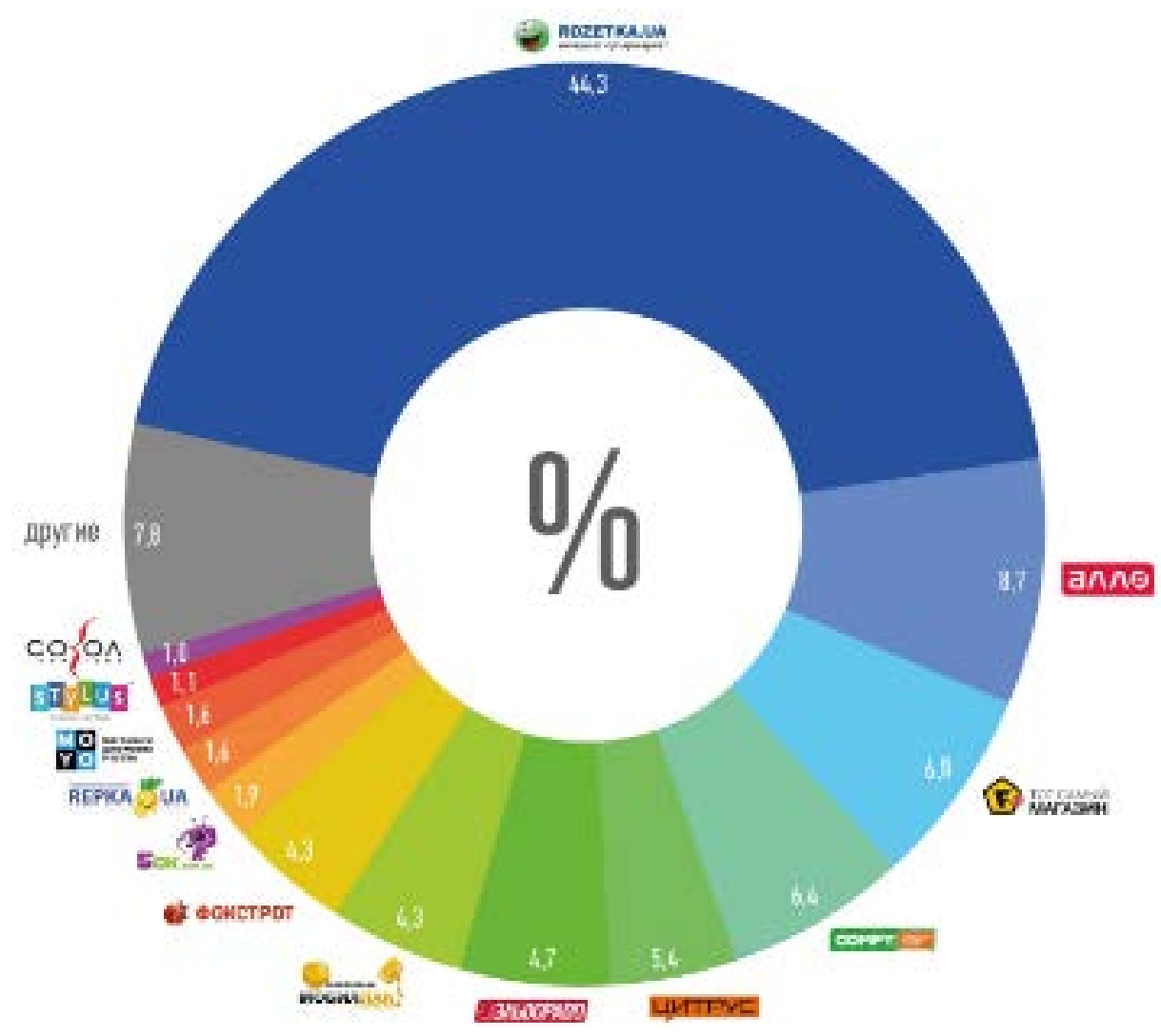

Figure 4. The structure of the e-commerce market of Ukraine in 2019

Source: (TOP 10 best online stores in Ukraine 2018-2019)

\section{The period - 2010 - to the present time.}

Highlights: the emergence of new platforms for online payments and services based on social networks, the widespread use of social networks as e-commerce sites or ways to obtain information about goods and services. Using the latest means of electronic interaction, companies also have the opportunity to obtain detailed information about the needs of each consumer and automatically offer goods and services in accordance with their requirements (the list of these events is formed on the basis of Table 1).

E-commerce markets have been growing around the world, especially since the mid-1990s, when the giants we know today, Amazon, Alibaba and others, emerged.

In fig. 1 shows that the development of Amazon is the most important factor in the development of the e-commerce market, at the same time, the activities of many other companies were effective. Offering a wide choice and exceptional convenience for customers, these companies have been able to quickly expand their activities through innovation and optimization.
Referring to the experience of e-commerce in Ukraine, in particular, it should be noted the growth of consumer activity in this area (Figure 2).

The leaders of the e-commerce market in Ukraine are the largest Ukrainian marketplace in Eastern Europe "Rozetka", as well as the Internet platforms "Allo" and "Citrus" (Figure 3 and Figure 4).

\section{Conclusions}

Thus, modern e-commerce shows a significant dynamics of development both in the world as a whole and in Ukraine. First of all, this fact is due to thefact that thisform of innovative entrepreneurship has many advantages over conventional stores and mail order catalogs. Consumers can easily, at any time convenient for them, look for the right product in a large database of these products and services. Online sellers, in turn, also receive certain benefits: the Internet and its search engines give customers the opportunity to reduce the cost of the advertising campaign. Even small online stores can enter global markets. Web technology also allows you to track customer preferences and implement personalized Internet marketing tools. 


\section{References:}

Roberts, M. L., \& Zahay, D. (2017). Internet Marketing: Integrating Online and Offline Strategies in a Digital Environment. Publisher: Cengage, 512 p.

Dvoretsky, D. Yu., Zharnikova, V. V., \& Soboleva-Tereshchenko, E. A. (2019). Features of loyalty programs of the B2B segment in the high-tech goods market. Science and Education a New Dimension. Humanities and Social Sciences, pp. 14-18.

Lazneva, I. O., \& Dolgopolova, M. V. (2019). Development of electronic trade in the structure of the information economy of Ukraine. Market infrastructure. No. 31, pp. 31-37.

Malovichko, S. V. (2015). Equifinal transformations in time and change of basic contours of electronic commerce of enterprises. Economic space. No. 98, pp. 25-34.

Melnychuk, O. (2014). Development of electronic commerce in the structure of the information economy of Ukraine. Bulletin of the Taras Shevchenko National University of Kyiv. Economy. No. 8, pp. 93-97.

Shaleva, O. I. (2011). E-commerce / Textbook. way. Kyiv: Center for Educational Literature, 216 p.

Zharnikova, V. V. (2019). World trends and current realities of retail development in the digital economy. Efficient economy. No. 5. URL: http://www.economy.nayka.com.ua/?op=1\&z=7075

Moore K. Ecommerce $101+$ The History of Online Shopping: What The Past Says About Tomorrow's Retail Challenges. URL: https://www.bigcommerce.com/blog/ecommerce/\#ecommerce-timeline

Hagiu, A., \& Wright, J. (2015). Marketplace or reseller? Management Science. Vol. 61. Issue 1, pp. 184-203. Malyuta, I. A., \& Ogol, A. E. (2019). Analysis of the current state and prospects of Internet commerce in Ukraine. Efficient economy. No. 1. URL: http://www.economy.nayka.com.ua/?op=1\&z=6845

10 global e-commerce trends of 2019 URL: https://evo.business/10-globalnyx-trendov-internettorgovli-2019-goda/

Worldwide Retail and Ecommerce Sales: eMarketer's Estimates for 2016-2021. URL: https://www.emarketer.com/Report/Worldwide-Retail-Ecommerce-Sales-eMarketers-Estimates$20162021 / 2002090$

Tardaskina, T. M., Strelchuk, E. M., \& Tereshko, Y. V. (2011). Electronic commerce [Text]: textbook. pos. Odessa: ONAZ them., 244 p.

Kaluzhsky, M. L. (2014). Electronic commerce: marketing networks and market infrastructure. Moscow: Economy, 328 p.

Khovrak, I. V. (2013). E-commerce in Ukraine: advantages and disadvantages. Economics. Finances. Right. No. 4.

United States: retail e-commerce sales 2017-2024 / Published by J. Clement, Feb 6, 2020. URL: https://www.statista.com/statistics/272391/us-retail-e-commerce-sales-forecast/

TOP 10 best online stores in Ukraine 2018-2019. URL: https://my-master.net.ua/ua/top-10-krashhihinternet-magaziniv-ukrayini-2018-2019-roku/ 